\title{
Effect of music intervention on the cognitive and depression status of senior apartment residents in Taiwan
}

\author{
Shu-Yu Tai ${ }^{1,2}$ \\ Ling-Chun Wang ${ }^{3}$ \\ Yuan-Han Yang ${ }^{3-6}$ \\ 'Department of Family Medicine, \\ Kaohsiung Municipal Ta-Tung \\ Hospital, ${ }^{2}$ Department of Family \\ Medicine, Kaohsiung Medical \\ University Hospital, Kaohsiung \\ Medical University, ${ }^{3}$ Mentality \\ Protection Center, Fo Guang Shan \\ Compassion Foundation, ${ }^{4}$ Department \\ of Neurology, Kaohsiung Medical \\ University Hospital, Kaohsiung \\ Medical University, ${ }^{5}$ Department \\ of Master's Program in Neurology, \\ Faculty of Medicine, Kaohsiung \\ Medical University, ${ }^{6}$ Department \\ of Neurology, Kaohsiung Municipal \\ Ta-Tung Hospital, Kaohsiung Medical \\ University, Kaohsiung City, Taiwan
}

Correspondence: Yuan-Han Yang Department of Neurology, Kaohsiung Municipal Ta-Tung Hospital, Kaohsiung Medical University, No 68, Jhonghua 3rd Road, Cianjin District, Kaohsiung City 80I45, Taiwan

Tel +886 7 29 I I 237 ext 20 I

Fax +88672911590

Email endlessyhy@gmail.com
This article was published in the following Dove Press journal:

Neuropsychiatric Disease and Treatment

12 June 2015

Number of times this article has been viewed

Objective: To identify the effect of music intervention on cognitive function and depression status of residents in senior citizen apartments based on the existing evidence regarding music therapy.

Methods: An experimental study was conducted from November 2008 to December 2009 . Sixty healthy senior apartment residents over 65 years of age were recruited and separated into two groups. According to their opinion, 41 took part in the music intervention group and 19 in the comparison group. The music intervention involved Buddhist hymns. The short-term effects were evaluated based on the measurement of cognitive function and depression level using the Mini-Mental State Examination (MMSE) and the Geriatric Depression Scale-short form (GDS-SF) at the baseline, 1 month, and 4 months.

Results: The means of the initial and the 1-month MMSE and GDS-SF scores did not differ between the two groups. The 4-month MMSE score significantly declined compared with the initial level in the comparison group, whereas no significant change was observed in the experimental group. Moreover, the 4-month GDS-SF score significantly improved in both groups compared with the initial level.

Conclusion: Music intervention may postpone cognitive decline in healthy residents preferring Buddhist hymns in the senior citizen apartments in 4 months follow-up, and intense contact with participants may improve their mood status.

Keywords: music intervention, cognitive function, depression, senior apartment residents

\section{Introduction}

The rapid increase in the elderly population has become a crucial medical problem in developed countries. ${ }^{1,2}$ The proportion of elderly population ( $\geq 65$ years) in the total population of Taiwan has risen continually over the past three decades from $4.1 \%$ in 1980 to $11.5 \%$ in 2013, representing the highest rate of aging worldwide. ${ }^{3}$ Along with the rapid increase in the elderly population and the decreased number of newborns (from approximately 322,938 in 1994 to 199,113 in 2013) in Taiwan, elderly care-related practices have increasingly gained attention. In addition, the structure of Taiwanese families is changing to only second-generation structure consisting of young couples and their children. ${ }^{4}$ Support for aging adults from their adult children and from health insurers is currently less reliable than it was previously. ${ }^{4}$ Because of the changes in family structure and the aging population trend, the demand for a convenient and safe home environment for aging adults has prompted the government to build or renovate apartment complexes for the senior population.

The number of senior citizen apartments has risen since 1995; these apartments provide an ideal retirement residence for healthy older adults. The government has 
funded four senior apartments in northern Taiwan and two in southern Taiwan. Songhl is the first senior citizen apartment in southern Taiwan, consisting of 12 stories above the ground and one basement floor, and providing 180 suites and well-designed disabled access facilities. The construction of this apartment commenced in February 1992 and was funded by the Department of Internal Affairs. The property is owned by the Kaohsiung County Government. The building was managed by the Fo Guang Shan Compassion Foundation from 1995 to 2011 and has been managed by the Tsui-Wen Foundation since 2012.

Senior apartment residents typically exhibit cognitive decline and depressed moods. ${ }^{5,6}$ Previous studies have observed a high prevalence of depressive symptoms $(39.2 \%-43.3 \%)^{7,8}$ and cognitive impairment $(18.6 \%)^{9}$ among aging adults in Taiwan; however, only a low proportion of them have received appropriate intervention. Depression and cognitive impairment may lead to morbidity and mortality among aging adults. ${ }^{10,11}$ Early detection and appropriate interventions to postpone cognitive decline and improve mood status are crucial concerns for health care systems worldwide.

Non-pharmacological interventions, which are recommended for behavioral and psychological symptoms in elderly patients, may be considered superior to pharmacological interventions because they produce few side effects. ${ }^{12-14}$ Music therapy is one of the non-pharmacological interventions. ${ }^{15-17}$ The development of music therapy in Taiwan may be traced back to early 1990s and corresponds with some cultural trends. ${ }^{18}$ Initially, music therapy in Taiwan was applied on children of delayed development; ${ }^{19}$ patients with anxiety, ${ }^{20}$ depression, ${ }^{21}$ or sleeping problem; ${ }^{22,23}$ and various populations for pain relief, ${ }^{24}$ and recently, it has been applied in long-term care settings, particularly in people with dementia. ${ }^{25,26}$ The programs included group music therapy, ${ }^{27}$ background music, ${ }^{28}$ and preferred music listening. ${ }^{29}$ Previous studies have indicated that music is beneficial in managing behavioral symptoms and anxiety in nursing home residents with dementia in Taiwan, ${ }^{25,26}$ but little is known regarding senior apartment residents.

Moreover, various components of music therapies might lead to various outcomes, particularly in diverse treatment targets. ${ }^{25,26,30-34}$ Buddhist hymns and religious music have frequently been used in meditation practices, which have various health benefits, including the possibility of preserving cognition and preventing dementia. ${ }^{35}$ Besides, they are also used to calm and improve the moods of Chinese aging adults. ${ }^{18,36}$ Buddhist hymns are frequently used in the general population; however, few studies have examined the effect of these hymns on healthy aging adults.

We aimed to evaluate the effects of Buddhist hymns on the mood and cognitive function of healthy aging adults residing in senior apartments.

\section{Materials and methods}

We conducted a pretest-posttest comparison study to evaluate the effect of music intervention on the level of cognition and depression in healthy senior apartment aging adults. The study was carried out from November 1, 2008 to December 1, 2009. Informed consent was obtained from the participants who agreed to join the study. All procedures were approved by the Institutional Review Board of Kaohsiung Medical University Chung-Ho Memorial Hospital.

\section{Participants}

The participants were recruited from the Songhl senior citizen apartment in Taiwan. We recruited participants of age 65 years or above and excluded those with any of the following criteria: 1) a diagnosis of dementia (based on the Diagnostic and Statistical Manual of Mental Disorders, 5 th edition, text revision) or an ascertainment of dementia 8 score greater than or equal to $2 ;^{37} 2$ ) severe hearing impairment; 3 ) the presence of severe physical or psychological symptoms; and 4) unwillingness or inability to participate in this experimental study. A total of 60 participants who met the inclusion criteria were invited and consented to participate in the study. According to the participants' opinion, 41 took part in the experimental group and 19 in the comparison group.

\section{Music intervention}

In Asian countries, Buddhist hymns, a type of Buddhist harmonic music, are often used in meditation to stabilize people's mind. ${ }^{38}$ The music therapist chose two specific Buddhist hymns (Reciting Buddha's Name and Omanipamihome by Voice of Ganges Co., Ltd.) and randomly assigned one song to the experimental group.

\section{Measurement outcomes}

\section{Mini-Mental State Examination}

We used the Chinese version of the Mini-Mental State Examination (MMSE), which was developed and revised by Folstein et $\mathrm{al}^{39}$ to assess cognitive function. The MMSE consists of eleven items and a total score of $30 .{ }^{39}$ A previous study of the Taiwanese population suggested that cognitive impairment should be defined as an MMSE score $<24$ in 
people with fewer than 6 years of formal education or $<26$ in those who have received more than 6 years of formal education. ${ }^{40}$

\section{Geriatric Depression Scale-short form}

We used the Chinese version of the Geriatric Depression Scale-short form (GDS-SF) ${ }^{41}$ to assess depression status. The GDS-SF, which consists of 15 items answered using a yes/no response, is a widely used depression screening device specifically designed for aging adults. ${ }^{42}$ After the score was revised for positive items, each item that elicited a yes answer received 1 point. Possible scores ranged from 0 to 15 . Researchers suggested using 8 as the cutoff point for a depressive tendency (sensitivity $96.3 \%$, specificity $87.5 \%$ ). ${ }^{43}$ The GDS-SF exhibits high internal consistency and test-retest reliability. ${ }^{44}$

\section{Procedure}

The participants in the experimental group were given a Buddha machine, and they listened to the 30-minute Buddhist hymns using the Buddha machine alone twice a day (in the morning and before bedtime) from Monday to Friday for 4 months. They also took a note if they finished their daily music therapy. The participants in the comparison group received only typical care, same as that in the experimental group, and did not undergo the therapeutic music intervention during the study period. The typical care matched the typical standard care that the participants in the experimental group received, which included the 24-hour residential care, such as those related to daily living, meal provision, well-trained social worker counseling, health counseling, and social activities (leisure and lifelong educational activities). Trained researchers contacted all participants each week by telephone to confirm that they were participating in their program and to provide an impetus for them to continue to be engaged in the study. Trained researchers assessed all participants' levels of cognition and depression by using the MMSE and GDS at the baseline, 1 month, and 4 months.

\section{Data analysis}

SPSS for Windows 17.0 (SPSS Inc., Chicago, IL, USA) was used for data analysis. Descriptive statistics were used to summarize the sample characteristics and variables of interest, frequency distributions were determined for nominal data (sex and educational level), and means and standard deviations were calculated for continuous data (age, MMSE score, and GDS score). The paired $t$-test analysis of covariance was used to compare the differences in cognition scores and depression scores between the groups over time.

\section{Result}

Table 1 shows the demographic characteristics of the participants in each group. A total of 60 participants were recruited for this study; 41 participants took part in the experimental group and 19 participants in the comparison group. All the participants completed the 1-month assessment. Three participants (15.8\%) in the comparison group and 14 participants (34.1\%) in the experimental group did not complete the 4-month assessment.

The average age of the participants was $80.87 \pm 7.78$ years (mean \pm SD). The sample consisted of slightly more women than men (women/men: 32/28). We categorized the educational level into three groups ( $0-6$ years, $7-9$ years, and $>9$ years). There were $53.7 \%$ of participants in the experimental group and $42.1 \%$ of participants in the comparison group with more than 9 years of education (Table 1 ). The mean $( \pm$ SD) MMSE scores of the experimental and comparison groups were 26.37 \pm 3.01 and 25.89 \pm 3.54 , respectively. The mean $( \pm$ SD) GDS scores of the experimental and comparison groups were 3.02 \pm 3.00 and $2.37 \pm 1.98$, respectively. No statistically significant differences were observed in age $(P=0.573)$, sex $(P=0.941)$, education $(P=0.613)$, initial MMSE score $(P=0.591)$, or GDS score ( $P=0.373$ ) between the experimental and comparison groups.

\section{MMSE and GDS scores}

The changes in the MMSE and GDS scores at the 1-month assessment relative to the initial values were non-significant in both the experimental and comparison groups (MMSE: $t$-test value $=-0.204, P=0.840$ in the experimental group vs $t$-test value $=-0.288, P=0.776$ in the comparison group; GDS: $t$-test value $=-0.413, P=0.682$ in the experimental group vs $t$-test value $=0.445, P=0.662$ in the comparison group)

Table I Demographic characteristics of participants

\begin{tabular}{|c|c|c|c|}
\hline & \multicolumn{3}{|c|}{ Participants $(\mathrm{N}=60)$} \\
\hline & $\begin{array}{l}\text { Experimental } \\
\text { group }(\mathrm{N}=4 \mathrm{I})\end{array}$ & $\begin{array}{l}\text { Control } \\
\text { group }(\mathrm{N}=19)\end{array}$ & $P$-value \\
\hline Age, mean \pm SD (years) & $80.49 \pm 8.88$ & $81.68 \pm 4.68$ & 0.573 \\
\hline \multicolumn{4}{|l|}{ Sex } \\
\hline Female, N (\%) & $22(53.7)$ & $10(52.6)$ & $0.94 I$ \\
\hline \multicolumn{4}{|l|}{ Educational level (years) } \\
\hline $0-6, N(\%)$ & $16(39.0)$ & $10(52.6)$ & 0.613 \\
\hline 7-9, N (\%) & $3(7.3)$ & I (5.3) & \\
\hline$>9, \mathrm{~N}(\%)$ & $22(53.7)$ & $8(42.1)$ & \\
\hline \multicolumn{4}{|l|}{ Initial MMSE } \\
\hline Mean \pm SD & $26.37 \pm 3.01$ & $25.89 \pm 3.54$ & 0.591 \\
\hline \multicolumn{4}{|l|}{ Initial GDS } \\
\hline Mean $\pm S D$ & $3.02 \pm 3.00$ & $2.37 \pm 1.98$ & 0.373 \\
\hline
\end{tabular}


(Table 2). Compared with the initial MMSE score, the 4-month MMSE score significantly declined in the comparison group ( $t$-test value $=-2.431, P=0.028)$; however, the difference was non-significant in the experimental group $(t$-test value $=-1.961$, $P=0.060)$. Compared with the initial GDS score, the 4-month GDS score significantly improved in both groups ( $t$-test value $=-4.483, P<0.001$ in the experimental group and $t$-test value $=-3.942, P=0.001$ in the comparison group).

\section{Discussion}

This experimental study was conducted to investigate the effects of Buddhist hymns on cognitive function and depression in healthy residents preferring Buddhist hymns in a senior citizen apartment. The results obtained over the 4-month follow-up period revealed a significant difference between the two groups in cognitive scores. After 4 months, a significant decline in the MMSE score compared with the initial score was observed in the comparison group, but not in the experimental group. Both groups exhibited significant improvement in GDS scores after 4 months compared with the initial GDS scores.

During the aging process, the MMSE score would decrease. ${ }^{45-48}$ In our study, a fall in the MMSE score was noted in both the experimental and comparison groups; however, the decrease in the MMSE score of the experimental group was non-significant compared with the initial score. The results indicate that our intervention, Buddhist hymns, may be beneficial for cognitive function in aging and preferring Buddhist hymns adults, although the study period is only 4 months. A few studies have observed similar findings. ${ }^{49}$

An examination of changes in depressed mood conducted using the GDS revealed that, between the baseline and the 1-month assessment, no significant reduction was observed in the depression score. However, significant changes were observed in the two groups between the baseline and the 4-month assessment. These changes may be attributed to the personal care that our staff and colleagues provided to each participant. Our staff in the senior apartment reminded and notified all participants in both the comparison and experiment groups to keep them engaged in the study. Such courtesies may improve participants' moods, thus reducing the depression score after 4 months. In further studies, we should also compare the mood status of the participants with that of other residents without intense contact with our staff.

Previous studies regarding the benefits of music therapy have focused on dementia patients or institutionalized residents (nursing home or long-term care institutions). These studies have observed that music therapy exerts beneficial effects on behavioral symptoms and anxiety. ${ }^{12,50-54}$ Certain studies have focused on the effect of music therapy on depression and cognition. ${ }^{55,56}$ Irish et $\mathrm{al}^{56}$ observed that a relaxing music background reduces anxiety levels and thus encourages autobiographical memory recall. These results confirm the findings observed by Thompson et al. ${ }^{57}$ Chu et al ${ }^{55}$ observed that group music intervention is a non-invasive and inexpensive therapy that reduces depression in aging adults and delays the deterioration of cognitive functions, particularly short-term recall among aging adults with mild and moderate dementia. Previous studies have focused on aging adults with dementia. ${ }^{12,25,26,31-33}$ Our study is the first to investigate the effects of music intervention on cognitive function and depression in healthy residents in a senior citizen apartment. All residents in a senior citizen apartment were required to undergo a blood test, chest X-ray, psychological assessment, and general physical examination annually to continue living in the senior citizen apartment; therefore, bias caused by medical conditions was not a concern. In addition, we referred to the recorded note of each participant to ensure that all participants met the protocol requirements. Furthermore, we continued the music intervention throughout our study for 4 months to decrease the residual effects and assess the long-term therapy effects; this intervention duration exceeds that used for 4-8 weeks in previous studies..$^{25-27,58}$

This study has several limitations, including the small sample size, lack of randomization, and a high drop-out rate in the experimental group. An analysis of the high

Table 2 Effect of music reminiscence therapy on MMSE and GDS scores

\begin{tabular}{|c|c|c|c|c|}
\hline & Initial & First month & Fourth month & $P$-value \\
\hline \multicolumn{5}{|l|}{ MMSE $($ mean $\pm S D, N)$} \\
\hline Experimental $(\mathrm{N}=4 \mathrm{I})$ & $26.37 \pm 3.01,41$ & $26.46 \pm 2.23,41$ & $25.1 I \pm 2.7 I, 28$ & $0.840^{*}, 0.060^{\#}$ \\
\hline Control $(\mathrm{N}=19)$ & $25.89 \pm 3.54,19$ & $26.05 \pm 2.91,19$ & $24.8 I \pm 3.4 I, 16$ & $0.776^{*}, 0.028^{\#}$ \\
\hline \multicolumn{5}{|l|}{ GDS (mean $\pm \mathrm{SD}, \mathrm{N})$} \\
\hline Experimental $(\mathrm{N}=4 \mathrm{I})$ & $3.02 \pm 3.00,4 I$ & $2.83 \pm 2.19,41$ & $0.26 \pm 0.59,27$ & $0.682^{*},<0.00 \mathrm{I}^{\#}$ \\
\hline Control $(\mathrm{N}=19)$ & $2.37 \pm 1.98,19$ & $2.63 \pm 2.22,19$ & $0.13 \pm 0.34,16$ & $0.662 *, 0.00 I^{\#}$ \\
\hline
\end{tabular}

Notes: *First month compared to initial. "Fourth month compared to initial.

Abbreviations: MMSE, Mini-Mental State Examination; GDS, Geriatric Depression Scale. 
drop-out rate in the experimental group revealed that the participants could not accommodate the intense frequency of the music therapy. However, the characteristics of these drop-out participants were not significantly different from the remaining ones ( $P=0.755$ for sex, $P=0.281$ for age, and $P=0.056$ for education level). Maybe it is worth to modify the frequency of interventions in order to adjust the therapeutic procedure to participants' possibilities and their conditions in the further study. Another weak point of this study is the quasi-experimental design without randomized and placebo-controlled groups due to ethical concerns and clinical outpatient investigations. It might have the bias of expected psychological and placebo effects of music intervention in the music group. Whether we would be more intent to treat with better effect is worthy of future investigation. The other limitation is that we did not have other demographic information (such as family history or support), which could influence the cognitive and mood status.

In the future, a randomized clinical trial with a larger sample size, a suitable frequency of interventions, and adequate demographic information should be conducted.

\section{Conclusion}

This study showed that music intervention may slow the cognitive decline in healthy residents preferring Buddhist hymns in the senior citizen apartment, and intense contact with participants may improve their mood status. However, additional randomized studies using a larger sample size based on appropriate calculations, measurements after the intervention, and long-term follow-up are required to verify the effect of music intervention on cognitive function and depression in healthy residents of senior citizen apartments.

\section{Acknowledgments}

We appreciate the participation of the residents of the Songhl senior citizen apartment and the cooperation of the apartment staff. This study was funded by the Mentality Protection Center and Fo Guang Shan Compassion Foundation.

\section{Disclosure}

The authors have no conflicts of interest to declare.

\section{References}

1. Nowrangi MA, Rao V, Lyketsos CG. Epidemiology, assessment, and treatment of dementia. Psychiatr Clin North Am. 2011;34(2):275-294,vii.

2. Ritchie K, Lovestone S. The dementias. Lancet. 2002;360(9347): 1759-1766.

3. The China Post news staff. Taiwan Must Address the Challenges of an Aging Society. China Post. 2013 October 13. Available from: http:// www.chinapost.com.tw/editorial/taiwan-issues/2013/10/13/391104/ Taiwan-must.htm.
4. Ministry of the Interior. Population Policy White Paper: Strategies towards declining fertility, ageing population, and immigration problems. Taipei, Taiwan: 2008. Chinese.

5. Catindig JA, Venketasubramanian N, Ikram MK, Chen C. Epidemiology of dementia in Asia: insights on prevalence, trends and novel risk factors. J Neurol Sci. 2012;321(1-2):11-16.

6. Brookmeyer R, Gray S, Kawas C. Projections of Alzheimer's disease in the United States and the public health impact of delaying disease onset. Am J Public Health. 1998;88(9):1337-1342.

7. Ku YC, Liu WC, Tsai YF. Prevalence and risk factors for depressive symptoms among veterans home elders in Eastern Taiwan. Int J Geriatr Psychiatry. 2006;21(12):1181-1186.

8. Tsai YF, Yeh SH, Tsai HH. Prevalence and risk factors for depressive symptoms among community-dwelling elders in Taiwan. Int J Geriatr Psychiatry. 2005;20(11):1097-1102.

9. Lin C-S, Lin M-H, Peng L-N, Chen L-K, Hwang S-J, Lan C-F. Screening cognitive impairment among institutionalized older Chinese men in Taiwan: a new minimum data set-based dementia screening tool is needed. Arch Gerontol Geriatr. 2011;53(1):e25-e28.

10. Tierney MC, Naglie G, Upshur R, et al. Factors associated with primary care physicians' recognition of cognitive impairment in their older patients. Alzheimer Dis Assoc Disord. 2014;28(4):320-325.

11. Fu CC, Lee YM, Chen JD. Association between depressive symptoms and twelve-year mortality among elderly in a rural community in Taiwan. J Formos Med Assoc. 2003;102(4):234-239.

12. Ueda T, Suzukamo Y, Sato M, Izumi S. Effects of music therapy on behavioral and psychological symptoms of dementia: a systematic review and meta-analysis. Ageing Res Rev. 2013;12(2):628-641.

13. Huybrechts KF, Gerhard T, Crystal S, et al. Differential risk of death in older residents in nursing homes prescribed specific antipsychotic drugs: population based cohort study. BMJ. 2012;344:e977.

14. Wang PS, Schneeweiss S, Avorn J, et al. Risk of death in elderly users of conventional vs atypical antipsychotic medications. $N$ Engl J Med. 2005;353(22):2335-2341.

15. Croom AM. Music, neuroscience, and the psychology of well-being: a precis. Front Psychol. 2012;2:393.

16. Croom AM. The practice of poetry and the psychology of well-being. $J$ Poet Ther. 2014;28(1):21-41.

17. Croom AM. Music practice and participation for psychological wellbeing: a review of how music influences positive emotion, engagement, relationships, meaning, and accomplishment. Musicae Scientiae. 2015;19(1):44-64.

18. Good M, Chin CC. The effects of Western music on postoperative pain in Taiwan. Kaohsiung J Med Sci. 1998;14(2):94-103.

19. Chang SM, Sung HC. [Music therapy and child care]. J Nursing (Hu li za zhi). 2005;52(6):71-75. Chinese.

20. Lai HL, Chen PW, Chen CJ, Chang HK, Peng TC, Chang FM. Randomized crossover trial studying the effect of music on examination anxiety. Nurse Educ Today. 2008;28(8):909-916.

21. Hsu WC, Lai HL. Effects of music on major depression in psychiatric inpatients. Arch Psychiatr Nurs. 2004;18(5):193-199.

22. Lai HL, Good M. Music improves sleep quality in older adults. $J A d v$ Nurs. 2005;49(3):234-244.

23. Chan MF. A randomised controlled study of the effects of music on sleep quality in older people. J Clin Nurs. 2011;20(7-8):979-987.

24. Lim PH, Locsin R. Music as nursing intervention for pain in five Asian countries. Int Nurs Rev. 2006;53(3):189-196.

25. Ho SY, Lai HL, Jeng SY, Tang CW, Sung HC, Chen PW. The effects of researcher-composed music at mealtime on agitation in nursing home residents with dementia. Arch Psychiatr Nurs. 2011;25(6): e49-e55.

26. Sung HC, Chang SM, Lee WL, Lee MS. The effects of group music with movement intervention on agitated behaviours of institutionalized elders with dementia in Taiwan. Complement Ther Med. 2006;14(2):113-119.

27. Chen SL, Lin HC, Jane SW. Perceptions of group music therapy among elderly nursing home residents in Taiwan. Complement Ther Med. 2009;17(4):190-195. 
28. Tan LP. The effects of background music on quality of sleep in elementary school children. J Music Ther. 2004;41(2):128-150.

29. Sung HC, Chang AM, Lee WL. A preferred music listening intervention to reduce anxiety in older adults with dementia in nursing homes. J Clin Nurs. 2010;19(7-8):1056-1064.

30. Chen CJ, Sung HC, Lee MS, Chang CY. The effects of Chinese fiveelement music therapy on nursing students with depressed mood. Int J Nurs Pract. 2014;21(2):192-199.

31. Guetin S, Charras K, Berard A, et al. An overview of the use of music therapy in the context of Alzheimer's disease: a report of a French expert group. Dementia. 2013;12(5):619-634.

32. Sung HC, Lee WL, Li TL, Watson R. A group music intervention using percussion instruments with familiar music to reduce anxiety and agitation of institutionalized older adults with dementia. Int $J$ Geriatr Psychiatry. 2012;27(6):621-627.

33. Erkkilä J, Punkanen M, Fachner J, et al. Individual music therapy for depression: randomised controlled trial. Br J Psychiatry. 2011;199(2): $132-139$.

34. Talwar N, Crawford MJ, Maratos A, Nur U, Mcdermott O, Procter S. Music therapy for in-patients with schizophrenia: exploratory randomised controlled trial. Br J Psychiatry. 2006;189(5):405-409.

35. Xiong GL, Doraiswamy PM. Does meditation enhance cognition and brain plasticity? Ann N Y Acad Sci. 2009;1172(1):63-69.

36. Huang ST, Good M, Zauszniewski JA. The effectiveness of music in relieving pain in cancer patients: a randomized controlled trial. Int $J$ Nurs Stud. 2010;47(11):1354-1362.

37. Yang YH, Galvin JE, Morris JC, Lai CL, Chou MC, Liu CK. Application of AD8 questionnaire to screen very mild dementia in Taiwanese. Am J Alzheimers Dis Other Demen. 2011;26(2):134-138.

38. Nachman-Hunt N. Music and meditation. Adv Mind Body Med. 2009; 24(1):5.

39. Folstein MF, Folstein SE, McHugh PR. "Mini-mental state". A practical method for grading the cognitive state of patients for the clinician. J Psychiatr Res. 1975;12(3):189-198.

40. Guo NW, Liu HC, Wong PF. Chinese version and norms of the minimental state examination. $J$ Rehabil Med Assoc. 1988;16:52-59.

41. Burke WJ, Roccaforte WH, Wengel SP. The short form of the Geriatric Depression Scale: a comparison with the 30 -item form. $J$ Geriatric Psychiatry Neurol. 1991;4(3):173-178.

42. Yesavage JA, Brink TL, Rose TL, et al. Development and validation of a Geriatric Depression Screening Scale: a preliminary report. J Psychiatr Res. 1982;17(1):37-49.

43. Lee HCB, Chiu HFK, Kwok WY. Chinese elderly and the GDS short form: a preliminary study. Clin Gerontol. 1993;14:37-42.
44. Mui AC. Geriatric Depression Scale as a community screening instrument for elderly Chinese immigrants. Int Psychogeriatr. 1996;8(3):445-458.

45. Starr JM, Deary IJ, Inch S, Cross S, MacLennan WJ. Age-associated cognitive decline in healthy old people. Age Ageing. 1997;26(4): 295-300.

46. Yesavage JA, Sheikh JI, Friedman L, Tanke E. Learning mnemonics: roles of aging and subtle cognitive impairment. Psychol Aging. 1990; 5(1):133-137.

47. Yu ES, Liu WT, Levy P, et al. Cognitive impairment among elderly adults in Shanghai, China. J Gerontol. 1989;44(3):S97-S106.

48. Li G, Shen YC, Chen CH, Zhao YW, Li SR, Lu M. An epidemiological survey of age-related dementia in an urban area of Beijing. Acta Psychiatr Scand. 1989;79(6):557-563.

49. Ennis EM Jr, Kazer MW. The role of spiritual nursing interventions on improved outcomes in older adults with dementia. Holist Nurs Pract. 2013;27(2):106-113.

50. de 1'Etoile SK. Neurologic music therapy: a scientific paradigm for clinical practice. Music Med. 2010;2(2):78-84.

51. Sakamoto M, Ando H, Tsutou A. Comparing the effects of different individualized music interventions for elderly individuals with severe dementia. Int Psychogeriatr. 2013;25(5):775-784.

52. Svansdottir HB, Snaedal J. Music therapy in moderate and severe dementia of Alzheimer's type: a case-control study. Int Psychogeriatr. 2006;18(04):613-621.

53. Koger SM, Chapin K, Brotons M. Is music therapy an effective intervention for dementia? A meta-analytic review of literature. J Music Ther. 1999;36(1):2-15.

54. Koelsch S. A neuroscientific perspective on music therapy. Ann NY Acad Sci. 2009;1169(1):374-384.

55. Chu H, Yang CY, Lin Y, et al. The impact of group music therapy on depression and cognition in elderly persons with dementia: a randomized controlled study. Biol Res Nurs. 2014;16(2):209-217.

56. Irish $\mathrm{M}$, Cunningham $\mathrm{CJ}$, Walsh JB, et al. Investigating the enhancing effect of music on autobiographical memory in mild Alzheimer's disease. Dement Geriatr Cogn Disord. 2006;22(1):108-120.

57. Thompson RG, Moulin CJ, Hayre S, Jones RW. Music enhances category fluency in healthy older adults and Alzheimer's disease patients. Exp Aging Res. 2005;31(1):91-99.

58. Chang FY, Huang HC, Lin KC, Lin LC. The effect of a music programme during lunchtime on the problem behaviour of the older residents with dementia at an institution in Taiwan. J Clin Nurs. 2010; 19(7-8):939-948.
Neuropsychiatric Disease and Treatment

\section{Publish your work in this journal}

Neuropsychiatric Disease and Treatment is an international, peerreviewed journal of clinical therapeutics and pharmacology focusing on concise rapid reporting of clinical or pre-clinical studies on a range of neuropsychiatric and neurological disorders. This journal is indexed on PubMed Central, the 'PsycINFO' database and CAS,

\section{Dovepress}

and is the official journal of The International Neuropsychiatric Association (INA). The manuscript management system is completely online and includes a very quick and fair peer-review system, which is all easy to use. Visit http://www.dovepress.com/testimonials.php to read real quotes from published authors. 